\title{
A COMPETIÇÃO ENTRE NÓS E A GENTE NAS FUNÇÕES DE COMPLEMENTO E ADJUNTO: DESVENDANDO OUTRAS PORTAS DE ENTRADA PARA O PRONOME INOVADOR
}

\author{
Juliana Barbosa de Segadas Vianna* \\ Célia Regina dos Santos Lopes**
}

Resumo: A substituição de nós por a gente na posição de sujeito pode ser considerada um processo de mudança em curso no português do Brasil como atestam as descrições feitas nas diversas regiões do país. Neste estudo, propomos estender a análise para as demais funções sintáticas, observando as formas variantes de primeira pessoa do plural como complemento de verbo e de nome. Levamos em conta, no primeiro caso, as funções de: (i) acusativo; (ii) dativo; (iii) oblíquo complemento de verbo; e (iv) oblíquo adjunto de verbo. No segundo caso, o estudo da variação das formas de nós e a gente no interior do sintagma nominal procura dar conta das seguintes funções: (i) complemento de nome, e (ii) adjunto de nome. Seguindo a orientação da sociolinguística de base laboviana, a análise quantitativa parte de entrevistas feitas na cidade do Rio de Janeiro. Os resultados encontrados mostram que formas do paradigma de a gente são mais frequentes no sintagma verbal, ao passo que, no interior do sintagma nominal, o uso das formas do paradigma de nós ainda se mantém produtivo.

Palavras-chave: Variação linguística; pronomes pessoais; acusativo; dativo; oblíquo.

Abstract: The replacement of nós by a gente ("we") in the position of the subject can be considered an ongoing process of change in Brazilian Portuguese. This phenomenon occurs in various regions of the country. We propose to analyze other syntactic functions. Our goal is to observe the variants as verb and noun complement. In the first case, we analyze namely: (i) accusative, (ii) dative, (iii)

* Universidade Federal do Rio de Janeiro/CNPq

** Universidade Federal do Rio de Janeiro/CNPq/FAPERJ. 
oblique complement, and (iv) oblique adjunct. In the second case, we study (i) name complement; (ii) name adjunct. Following the orientation of Labovian sociolinguistics, the quantitative analysis was based on interviews conducted in Rio de Janeiro City. The results show that the new pronoun a gente is more frequent in clausal phrase, while the old pronoun nós still remains productive in noun phrase.

Keywords: Linguistic variation; personal pronouns; accusative; dative; oblique.

\section{Introdução}

A alternância entre nós e a gente, em posição de sujeito, tem sido amplamente descrita no português do Brasil (doravante PB), por diferentes grupos de pesquisa, focalizando distintas regiões do país. ${ }^{1}$ Os resultados dessas pesquisas indicam que o fenômeno de variação entre nós e a gente, na variedade brasileira, pode ser caracterizado como um processo de mudança linguística, no qual, gradativamente, a forma inovadora tem ocupado os espaços da forma mais antiga nós. Nesse processo de difusão de a gente na língua oral do PB, atuam, de maneira decisiva, dois importantes fatores: em primeiro lugar, o espraiamento crescente do pronome $a$ gente não só entre jovens, mas em todas as faixas etárias nos últimos 20 anos e, em segundo, o fato de não haver estigma associado ao uso da forma no desempenho oral dos falantes, mesmo entre os considerados cultos (LOPES, 1993, 2003; ZILLES, 2007).

\footnotetext{
${ }^{1}$ Para a região sudeste, há os estudos de Omena (1986, 1996, 2003), Lopes (1993), Machado (1995) no Rio de Janeiro, os trabalhos de Maia (2003) e Rocha (2009) em Minas Gerais e o estudo de Menon (1994) e de Mendonça (2010) que analisam São Paulo e Espírito Santo, respectivamente. A região sul foi vastamente estudada por Borba (1993), Lopes (1993), Seara (2000), Borges (2004), Zilles (2005, 2007), Laureano (2003) e Tamanine (2002, 2010). A região nordeste foi objeto de estudo de Álban \& Freitas (1991), Mendes (2007) com dados da Bahia; Fernandes (1997, 2004), na Paraíba; e Ramos et al. (2009), no Maranhão. Mattos (2009) descreve a região centro-oeste.
} 
Não obstante, no que se refere à alternância das formas de $1^{a}$ pessoa do plural em outras funções sintáticas, a pesquisa científica conta ainda com parcas descrições (OMENA, 1986, 1996, 2003; RAMOS ET $A L$., 2009). Utilizando-se, em seus comentários, da terminologia adotada na NGB, Omena (2003, p. 65) já aponta que "o uso de a gente por nós avançou mais em alguns contextos do que em outros: predomina na função de adjunto adverbial com a gente é bem mais frequente do que conosco, chegando a ser categórico entre as crianças". Lopes (2007) ressalta que a entrada das formas gramaticalizadas você e a gente no sistema de pronomes pessoais ocasionou uma série de reorganizações gramaticais, tanto no subsistema de possessivos, quanto no de pronomes que exercem função de complementos diretos ou indiretos. Retomando o trabalho pioneiro de Omena (1986, 2003), a autora afirma que:

Como complemento e sujeito, a gente é a forma preferida. Em contrapartida, na variação entre da gente, como adjunto adnominal, e o possessivo nosso(a) (s), há predomínio da forma conservadora e suas variantes. (LOPES, 2007, p. 115)

Há, entretanto, muitas perguntas ainda sem resposta. Por exemplo, (i) a implementação de a gente nas funções sintáticas diferentes de sujeito dá-se de maneira semelhante no sintagma verbal ou no interior do sintagma nominal?; (ii) quais os fatores favorecedores do uso de a gente nas funções de acusativo, dativo, (oblíquo) ${ }^{2}$ complemento e (oblíquo) adjunto?; (iii) existem contextos sintáticos que impedem a entrada do pronome inovador?

\footnotetext{
${ }^{2}$ As funções sintáticas de oblíquo complemento e de oblíquo adjunto são exclusivamente estabelecidas em relação a núcleos verbais (MATEUS ET AL., 2003). No caso de núcleos nominais, são estabelecidas relações de complementação e/ ou de adjunção que, por sua vez, guardam certo paralelo com as relações contraídas no sintagma verbal. Em função dessa proximidade de valores entre (i) oblíquo complemento (e um núcleo verbal)/ (ii) complemento nominal (e núcleo nominal), por um lado; e, por outro lado, entre (iii) oblíquo adjunto (e um núcleo verbal)/ (iv) adjunto (e núcleo nominal), optamos por indicar as relações de (oblíquo) complemento e (oblíquo) adjunto, respectivamente, entre parênteses conforme será discutido na seção 4.2.
} 
Tentando responder essas questões, o presente trabalho tem como objetivo desvendar o caminho através do qual a forma a gente gradativamente adentra e se espalha pelo sistema do $\mathrm{PB}$ usando outras portas de entrada, isto é, por meio de outras relações gramaticais, diferentes da função de sujeito.

\section{Hipóteses preliminares: de onde parte a investigação?}

Em pesquisa anterior, Vianna (2012) percebe diferenças bem acentuadas em relação à produtividade das formas de $1^{\mathrm{a}}$ pessoa do plural nas diversas relações gramaticais que se estabelecem com o núcleo verbal e/ou nominal, à semelhança do que outras pesquisas já apontavam (OMENA, 1986, 1996; RAMOS ET AL., 2009). Aparentemente, além da função de sujeito, a forma inovadora $a$ gente encontra sua porta de entrada para adentrar o sistema pronominal do português, principalmente, nas relações gramaticais oblíquas (MATEUS ET AL., 2003, p. 277-327). A alta proeminência discursiva e o caráter dêitico dos pronomes de $1^{\mathrm{a}}$ e $2^{\mathrm{a}}$ pessoas, obrigatoriamente [+humanos], favorecem a sua expressão plena para individualizar ou desambiguizar claramente o referente. Ao dizer "ele saiu com a gente/com você", o falante explicita o referente, elucidando que a ação foi realizada com a pessoa X e não com Y. Tal propriedade pode ainda ajudar a compreender por que as formas de $1^{\mathrm{a}}$ e $2^{\mathrm{a}}$ pessoas, mais do que as de $3^{\mathrm{a}}$ pessoa, ocorrem preferencialmente preenchidas como formas acusativas e dativas, até mesmo, como argumento externo (função de sujeito). ${ }^{3}$ Esse comportamento é fortemente identificado com as formas oriundas de processos de gramaticalização

\footnotetext{
${ }^{3}$ Os estudos que defendem que o PB está assumindo características de língua de sujeito pleno mostram que a primeira pessoa do singular, ainda que tenha morfologia forte, apresenta os maiores índices de preenchimento no PB. Para maiores informações, ver Duarte (1995) entre outros. Para o objeto nulo, a vasta produção sobre $\mathrm{O} P B$ destaca tal propriedade apenas na $3^{\mathrm{a}}$ pessoa e não nas duas primeiras: cf. Cyrino (1997), Duarte (1986, 1989), Corrêa (1991), Averbug (2000), Baltor (2003), Silva (2004), Freire $(2000,2005)$, entre tantos outros.
} 
de nomes a pronomes, como é o caso de a gente e você, em função do status informacional que esses elementos adquirem na função de complemento oblíquo, como mencionado anteriormente.

Como os estudos sobre gramaticalização postulam, tal processo é unidirecional, sempre partindo do discurso para a sintaxe (HEINE, 2003). Assim, a entrada da forma inovadora na relação gramatical que carrega o teor mais informacional estaria em perfeito acordo com o postulado básico do processo: o sentido discurso > sintaxe. Em outras palavras, a forma a gente estaria adentrando o sintagma oracional a partir das relações gramaticais mais periféricas em que há um caráter muito mais discursivopragmático do que sintático. Todavia, essas hipóteses carecem de maior investigação em um corpus mais amplo do PB.

No interior de sintagmas nominais, por sua vez, a entrada de a gente continua sendo bastante limitada. Em princípio, as relações internas ao sintagma nominal, principalmente quando são de adjunção (as mais produtivas nos dados), assumem um caráter muito mais fixo (imutável) na organização do sistema, isto é, são relações de caráter essencialmente sintático e não discursivo. Talvez por isso a entrada de $a$ gente nessas relações gramaticais seja tão desfavorecida.

Tendo em vista tais reflexões e os resultados discutidos em Omena $(1986,2003)$ e Vianna (2012), partimos das seguintes hipóteses:

(a) As relações gramaticais no sintagma verbal são favorecedoras de a gente, enquanto as relações gramaticais no interior do sintagma nominal funcionam por barrar a entrada do novo pronome no sistema pronominal do português (VIANNA, 2012);

(b) O princípio do paralelismo formal e semântico também se mostra relevante para o fenômeno quando se consideram as funções de complemento e adjunto (RAMOS ET AL., 2009) 


\section{Pressupostos teórico-metodológicos e corpus utilizado}

Adotando os pressupostos teóricos da sociolinguística quantitativa laboviana, utilizamos o programa computacional de regras variáveis, denominado Goldvarb 2001. Seguindo tal perspectiva, foram levantados dados de nós e a gente como complemento e adjunto, a partir de duas amostras do Projeto Bilateral Estudo comparado dos padrões de concordância em variedades africanas, brasileiras e europeias, contando com um total de 36 entrevistas. Tal conjunto de dados é representativo da variedade brasileira do português, mais especificamente os municípios do Rio de Janeiro e Nova Iguaçu (RJ) e encontra-se organizado com base em três dimensões de estratificação: sexo (homens e mulheres), faixa etária (de 18 a 35 anos, de 36 a 55 anos, e de 56 a 75 anos) e escolaridade (ensino fundamental, ensino médio e ensino superior).

Partindo de tais amostras, os dados localizados foram codificados de acordo com oito grupos de fatores, entre linguísticos e sociais, a saber: (1) tipos de núcleo ao qual as formas de nós ou a gente se subordinam; (2) relações gramaticais estabelecidas com o núcleo ao qual as formas se subordinam; (3) grau de determinação do referente semântico; (4) paralelismo formal e semântico; (5) sexo do informante; (6) faixa etária; (7) escolaridade do informante; e (8) região do informante.

Nas seções seguintes, apontaremos os resultados mais significativos da análise dos dados.

\section{Análise dos resultados}

Entre os grupos de fatores linguísticos e sociais controlados, cinco foram apontados como relevantes na alternância entre as formas dos paradigmas de nós e de a gente como complemento e adjunto, na seguinte ordem: 


\section{QUADRO 1}

Grupos de fatores relevantes na alternância das formas de $1^{\mathrm{a}}$ pessoa nas funções de complemento e adjunto

\begin{tabular}{|l|l|}
\hline $\mathbf{1}^{\mathbf{o}}$ & Relações gramaticais \\
$\mathbf{2}^{\mathbf{o}}$ & Tipos de núcleo \\
$\mathbf{3}^{\mathbf{0}}$ & Paralelismo formal e semântico \\
$\mathbf{4}^{\mathbf{o}}$ & Faixa etária do informante \\
$\mathbf{5}^{\mathbf{0}}$ & Escolaridade do informante \\
\hline
\end{tabular}

Tendo em vista tal resultado, chama a atenção a elevada importância dos grupos de fatores linguísticos referentes a (1) relações gramaticais estabelecidas entre as formas pronominais e o núcleo a que se subordinam e, por outro lado, (2) tipos de núcleo ao qual as formas de nós ou a gente se subordinam. O fato de dois grupos relacionados às diferentes funções sintáticas serem os primeiros selecionados pelo programa estatístico já pode elucidar uma diferença do comportamento das formas variantes quando em nível oracional ou no interior dos sintagmas nominais. Nas seções seguintes, essas e outras questões serão mais bem discutidas.

A seguir, será apresentado cada um dos grupos de fatores selecionados na rodada geral dos dados, começando pelos linguísticos e passando aos sociais, de acordo com a ordem de seleção efetuada pelo Programa Goldvarb 2001.

\subsection{Relações gramaticais}

O primeiro grupo de fatores selecionado diz respeito às relações gramaticais estabelecidas com as formas de nós e a gente, independentemente do núcleo a que se referem, seja nominal seja verbal. De acordo com os dados da pesquisa, foi possível observar quatro possíveis funções sintáticas que podem ser exercidas por formas de $1^{\mathrm{a}}$ pessoa do plural no interior do sintagma verbal ou do sintagma nominal, a saber: (i) acusativo, (ii) dativo, (iii) (oblíquo) complemento e (iv) (oblíquo) adjunto. Os exemplos 
de (01) a (04) ilustram os quatro tipos de relações gramaticais que foram localizados na amostra. A Tabela 1 , mais adiante, apresenta a frequência e o peso relativo de cada fator controlado para a aplicação de a gente:

\section{(01) Acusativo}

a. "Apesar que foi muita muvuca ela só/ela tratou a gente super bem..." (dado 1, Copa FA1)

b. "...eu acho que a imprensa ela tem uma grande parte em nos assustar..." (dado 135, Nova Iguaçu FA3)

(02) Dativo

a. “...não tem jeito aí manda pra gente... que é lá no Melhado Advogados..." (dado 21, Copa MA3)

b. “...ele veio dar a chance a nós de sermos felizes...” (dado 48, Copa FC1)

(03) (Oblíquo) Complemento

a. "Ela tava falando lá com a gente..." (dado 2, Copa FA1)

b. “...e a pessoa que ía ficar conosco lá...falava português...então no caso: eh/eh alemão mesmo né...” (dado125, Nova Iguaçu FA3)

c. “...se a gente paga impostos é pra esse dinheiro ser revertido em benefícios pra gente mas... infelizmente as escolas não têm estado né no nível adequado..." (dado 3, Copa MA2)

\section{(04) (Oblíquo) Adjunto}

a. “...minha mãe ia com a gente pra lá ou a gente ficava na casa da minha avó......" (dado 13, Copa MB3)

b. "e depois à noite tinha o jantar dos indianos pra nós..."(dado 69, Copa MC3)

c. "O medo da gente... é você ser jogado num hospital público... o qual você não tenha médico..." (dado159, Nova Iguaçu MB1)

d. "Eu acho que os nossos políticos eles estão muito mal preparados..." (dado152, Nova Iguaçu MB1) 
TABELA 1

Relações gramaticais

\begin{tabular}{l|c|c}
\hline & Freq. & PR $^{4}$ \\
\hline Acusativo & $24 / 37$ & \\
Dativo & $65 \%$ & 0.40 \\
& $7 / 12$ & \\
(Oblíquo) Complemento & $58 \%$ & 0.33 \\
& $11 / 12$ & \\
(Oblíquo) Adjunto & $92 \%$ & 0.98 \\
& $12 / 19$ & \\
& $63 \%$ & 0.41 \\
\hline
\end{tabular}

Fator de aplicação: a gente.

De acordo com a Tabela 1 , a relação gramatical que mais favorece o uso de a gente é a de (oblíquo) complemento. Foram localizados 11 dados de a gente em 12 ocorrências totais, isto é, 92\% de produtividade (PR 0.98). De acordo com o programa de regras variáveis Goldvarb 2001, nas demais relações gramaticais, apesar de as formas relacionadas a gente apresentarem sempre os percentuais de frequência mais altos, haveria o seu desfavorecimento em termos de peso relativo nas funções de: acusativo, dativo e (oblíquo) adjunto. Há de se ter em vista, ainda, que as relações gramaticais controladas se relacionam a diferentes níveis sintáticos, como será demonstrado na seção que se segue.

\subsection{Tipos de núcleo}

O segundo grupo de fatores selecionado diz respeito aos tipos de núcleo ao qual as formas relacionadas a nós ou a gente estão subordinadas. Nesse sentido, é possível constatar uma íntima relação entre este grupo de fatores e o grupo de fatores discutido

\footnotetext{
${ }^{4} \mathrm{PR}=$ Peso Relativo.
} 
em 4.1, relativo às relações gramaticais estabelecidas entre a forma pronominal e o núcleo. ${ }^{5}$

Como ilustrado nos exemplos de (01) a (04), as formas do paradigma de nós e a gente podem estar subordinadas a dois núcleos distintos: verbal ou nominal.

As relações gramaticais de acusativo e de dativo são exclusivamente identificadas em relação a um predicador verbal, como se observa em "só/ela tratou a gente super bem...” ou “... não tem jeito aí manda pra gente...", respectivamente. No entanto, as funções sintáticas de (oblíquo) complemento e (oblíquo) adjunto podem ser estabelecidas com relação a um núcleo verbal e/ou um núcleo nominal. No primeiro caso, como exemplificado anteriormente, teríamos, no nível oracional, os oblíquos verbais que funcionam como complementos ("Ela tava falando lá com a gente...") ou adjuntos ("minha mãe ia com a gente pra lá"). No segundo caso, quando no interior dos sintagmas nominais, há, semelhantemente, os dois tipos de relação: complemento de nome ("é pra esse dinheiro ser revertido em benefícios pra gente") e adjunto de nome ("O medo da gente... é você ser jogado num hospital público"). A Tabela 2 apresenta as frequências e os pesos relativos para aplicação de a gente, em sintagmas verbais e/ou em sintagmas nominais:

\footnotetext{
${ }^{5}$ Em função das relações gramaticais controladas estarem relacionadas a diferentes níveis sintáticos, pode ter havido a sobreposição entre as duas variáveis investigadas (relações gramaticais e os tipos de núcleo). Diante dos resultados obtidos, tal hipótese demandará, como passos metodológicos seguintes, que outras rodadas sejam efetuadas incluindo e excluindo uma e outra variável com o intuito de verificar, posteriormente, a possível alteração na seleção. Todavia, no presente artigo, interessa-nos apenas descrever os resultados gerais.
} 
TABELA 2

Tipos de núcleo

\begin{tabular}{l|c|c}
\hline & Freq. & PR \\
\hline Núcleo nominal & $20 / 145$ & \\
& $14 \%$ & 0.22 \\
Núcleo verbal & $54 / 80$ & \\
& $68 \%$ & 0.90 \\
\hline
\end{tabular}

Fator de aplicação: a gente.

Os resultados mostram que a entrada de a gente no sistema ocorre preferencialmente no nível oracional. Localizaram-se 54 dados de a gente, em 80 ocorrências totais, ou seja, houve 68\% de produtividade (PR 0.90). Em sintagmas nominais, por sua vez, o resultado é inverso. Há um enorme desfavorecimento da forma inovadora nesse nível sintático. Foram localizados apenas 20 dados de a gente, em um total de 145 ocorrências, isto é, houve apenas $14 \%$ de produtividade (PR 0.22).

Para a melhor compreensão dos resultados, realizamos um cruzamento do grupo de fatores relações gramaticais e o grupo de fatores relativo aos tipos de núcleo, apresentado na Tabela 3 a seguir:

TABELA 3

Distribuição geral dos dados de $1^{\mathrm{a}}$ pessoa do plural nas relações gramaticais de não-sujeito pelos tipos de núcleo

\begin{tabular}{l|c|c|c|c|c|c|c|c}
\hline \multicolumn{2}{c|}{ Acusativo } & \multicolumn{2}{c|}{ Dativo } & \multicolumn{2}{c}{ (Obl.) Compl. } & \multicolumn{2}{c}{ (Obl.) Adjunto } \\
\hline & nós & a gente & nós & a gente & nós & a gente & nós & a gente \\
\hline Núcleo & - & - & - & - & - & $7 / 145$ & $125 / 145$ & $13 / 145$ \\
nominal & & & & & & $5 \%$ & $86 \%$ & $9 \%$ \\
\hline Núcleo & $14 / 77$ & $19 / 77$ & $4 / 77$ & $7 / 77$ & $1 / 77$ & $12 / 77$ & $7 / 77$ & $13 / 77$ \\
verbal & $18 \%$ & $25 \%$ & $5 \%$ & $9 \%$ & $1 \%$ & $15 \%$ & $9 \%$ & $17 \%$ \\
\hline
\end{tabular}

As frequências gerais na Tabela 3 permitem tecer alguns comentários iniciais sobre o fenômeno de variação entre nós e a gente em outras funções sintáticas. Os resultados demonstram que no nível interno ao sintagma nominal - mais especificamente em relações gramaticais de adjunção - as formas relacionadas ao pronome primitivo nós (nesse caso, as formas possessivas nosso(s) e nossa(s)) 
se mantêm como estratégia preferencial em nossos dados, dificultando a entrada do pronome inovador a gente. Foram localizados 125 dados de formas do paradigma de nós, em 145 ocorrências totais nesse contexto sintático. Dito de outra maneira, as formas de nós registraram $86 \%$ de produtividade quando articuladas a um núcleo nominal, o que pode estar indicando que tal nível sintático ainda é refratário ao uso do pronome inovador. Nossos resultados confirmam o que foi observado por Omena $(1986,2003)$ em dados dos anos 80 com falantes de escolaridade média (amostra PEUL-RJ). Apesar de levarmos em conta outra classificação sintática, ratificamos em nossos dados que "há pouca incidência na função de adjunto adnominal - da gente, com preferência para o pronome possessivo - nosso(s), nossa (s)" (OMENA, 2003, p. 65).

Por outro lado, no sintagma verbal, a forma inovadora apresenta maiores índices de frequência em todos os contextos controlados. Tendo em vista as funções sintáticas diferentes de sujeito, é possível observar que o acusativo é a relação sintática mais produtiva ao uso de a gente, respondendo com $25 \%$ do total de ocorrências localizadas na amostra em nível oracional (isto é, subordinadas a um núcleo verbal). Esses resultados preliminares, aparentemente, indicam a forte inserção de a gente como complemento em núcleos verbais.

\subsection{Paralelismo formal e semântico}

O último grupo de fatores linguísticos selecionado pelo Programa Goldvarb 2001 foi o paralelismo formal e semântico. Essa variável, inclusive, é também apontada frequentemente como sendo a mais relevante (ou uma das mais relevantes) do ponto de vista estrutural, para a alternância, na posição de sujeito, entre nós e a gente em pesquisas que têm por base a variedade brasileira (VIANNA, 2011; VIANNA \& LOPES, 2012).

A hipótese que se relaciona ao paralelismo formal é a de que o falante tende a repetir uma mesma forma linguística na sequência discursiva (OMENA, 1986, 1993, 2003; LOPES, 1993). Em 
outras palavras, tendo em vista a presente investigação, a escolha da primeira forma pronominal condicionaria os usos subsequentes, desencadeando uma série de repetições da mesma forma linguística.

Com relação a essa variável, mesmo a primeira escolha da forma, que aparentemente não sofre influência de outra que a antecede, não é ao acaso, como defende Omena (2003, p.72).

A escolha da forma para a primeira referência é influenciada pela forma predominantemente utilizada pelo indivíduo. O que se dá com pouquíssimas exceções é que o falante em cujo desempenho predomina o uso de $a$ gente tem mais formas iniciais com a gente. O mesmo acontece com os que usam predominantemente nós, que tendem a utilizá-la nas suas referências iniciais. (OMENA, 2003, p.72)

Os trechos exemplificados de (05) a (09) ilustram os tipos de sequências discursivas controladas nas amostras estudadas:

(05) Primeira ocorrência na sequência discursiva

“...o Carrefour também era parte ... na: na contagem era para ficar com a gente também ... só que aí não não ... não ficou ..." (dado111, Nova Iguaçu MA3)

(06) Antecedido por a gente sujeito

“...se a gente paga impostos é pra esse dinheiro ser revertido em benefícios pra gente...” (dado3, Copa MA2)

(07) Antecedido por a gente em outras funções sintáticas

“... ele não sabia administrar o dinheiro dele é o que minha mãe conta pra gente porque eu também era muito pequena eu não lembro... ele ele trabalhou em muitas firmas boas se ele soubesse administrar o dinheiro dele... ele vinha ele vinha negócio de de restaurante trabalhou por exemplo/ tem meus tios que são irmão dele... todos eles têm uma vida razoável são taxi:sta... têm uma vida mais ou menos melhor do que a da gente né..." (dado111, Nova Iguaçu FA2)

(08) Antecedido por nós sujeito

“...então nós ficamos na casa dele... programo:u um passe:io e visi:tas em diversos lugares...aí ele apresentava falava com a gente... a gente falava com ele e ele traduzia pra pessoa..." (dado126, Nova Iguaçu FA3) 
(09) Antecedido por nós em outras funções sintáticas “...a consciência nossa é uma justiça muito...mas muito... muito drástica...com a gente...” (dado142, Nova Iguaçu MB1)

A Tabela 4 ilustra a produtividade de cada um dos fatores controlados:

TABELA 4

Paralelismo formal e semântico

\begin{tabular}{|c|c|c|}
\hline & Freq. & $\mathbf{P R}$ \\
\hline Primeira ocorrência & $\begin{array}{c}44 / 118 \\
37 \%\end{array}$ & 0.61 \\
\hline Antecedido por $a$ gente sujeito & $\begin{array}{c}14 / 41 \\
34 \%\end{array}$ & 0.53 \\
\hline Antecedido por a gente em outras funções & $\begin{array}{c}11 / 15 \\
73 \%\end{array}$ & 0.86 \\
\hline Antecedido por nós sujeito & $\begin{array}{l}3 / 16 \\
18 \%\end{array}$ & 0.10 \\
\hline Antecedido por nós em outras funções & $\begin{array}{c}2 / 35 \\
5 \%\end{array}$ & 0.18 \\
\hline
\end{tabular}

Fator de aplicação: a gente.

De acordo com os resultados, é possível depreender que o fator que mais impulsiona a ocorrência de a gente como complemento e adjunto é a ocorrência anterior da forma também em funções sintáticas diferentes de sujeito, com PR 0.86. Localizaram 11 dados de $a$ gente em um total de 15 ocorrências antecedidas por a gente em função sintática diferente de sujeito (73\%).

Por sua vez, a antecedência pela forma inovadora em posição de sujeito tem, aparentemente, peso neutro para aplicação da regra. Foram encontrados apenas 14 dados de a gente em outras funções sintáticas estando precedidos por a gente sujeito, em um total de 41 casos de atuação do fator. $O$ peso relativo aferido pelo programa estatístico foi de 0.53 .

Como era de se esperar, quando antecedido por nós seja em posição de sujeito seja em função sintática diferente - 
verificamos o desfavorecimento de a gente. Todavia, há algumas diferenças: o desfavorecimento é ainda maior quando o pronome nós se encontra na função de sujeito, com PR 0.10. Quando o pronome padrão se encontra em outra função sintática, há desfavorecimento na aplicação da regra, mas em escala menor: PR 0.18. Aparentemente, tal resultado pode ter sido impulsionado pela alta produtividade de dados de nosso/nossa na amostra. Os dois únicos casos de ocorrência de $a$ gente não-sujeito antecedido por nós não-sujeito ocorreram com a forma possessiva nosso. Os exemplos (10) e (11) ilustram as ocorrências aferidas na amostra.

(10) “...e foi morar ( ) lá pro lado de onde meu pai tinha um sítio era praticamente lá do outro lado da rua... uma casa que tinha então lá o: o nosso paraíso era lá... durante o ano inteiro era aqui... chegava época de férias... meu pai ficava trabalhando aqui minha mãe ia com a gente pra lá ou a gente ficava na casa da minha avó... aí ficava todo mundo lá na casa da minha avó eram praticamente eu acho que doze netos..." (dado142, Nova Iguaçu MB1)

(11) “... a consciência nossa é uma justiça muito...mas muito...muito drástica...com a gente...” (dado13, Nova Iguaçu MB3)

\subsection{Faixa etária do informante}

A variável faixa etária tem fundamental importância na investigação do comportamento linguístico de uma comunidade, uma vez que é capaz de sugerir se um dado fenômeno variável está em processo de mudança ou em variação estável.

Tendo em vista tal fator, foram controladas três faixas etárias nas amostras de língua oral, a saber: (i) de 18 a 35 anos, considerada relativa ao grupo dos jovens; (ii) de 36 a 55 anos, referente ao grupo dos adultos; e (iii) de 56 anos em diante, referente ao grupo de pessoas com idade mais avançada. A Tabela 5, a seguir, sintetiza os resultados encontrados na amostra analisada: 
TABELA 5

Faixa etária do informante

\begin{tabular}{c|c|c}
\hline & Freq. & PR \\
\hline 18-35 anos & $30 / 57$ & \\
& $52 \%$ & 0.73 \\
$36-55$ anos & $26 / 95$ & \\
& $27 \%$ & 0.49 \\
$56-75$ anos & $20 / 77$ & \\
& $25 \%$ & 0.32 \\
\hline
\end{tabular}

Fator de aplicação: a gente.

Nossos resultados evidenciam o favorecimento de a gente como complemento e adjunto, entre os indivíduos da faixa etária mais jovem (de 18 a 35 anos), com peso relativo 0.73 . Nessa faixa etária, foram localizados 30 dados de a gente, em um total de 57 ocorrências, ou seja, houve uma produtividade de $52 \%$ nas funções sintáticas diferentes de sujeito. Nas faixas etárias subsequentes, a produtividade de $a$ gente tende a diminuir, ocorrendo queda sucessiva do favorecimento da forma: PR 0.49, na faixa de 36 a 55 anos, e PR 0.32, na faixa de 56 a 75 anos.

Tal comportamento identificado em nossos dados reflete o que diversas pesquisas já apontavam em relação à posição de sujeito no PB. Inclusive, a variável faixa etária é a variável social que mais se destaca nas pesquisas que tratam da substituição de nós por a gente na posição de sujeito, sendo frequentemente apontada como um forte indicativo de mudança linguística na comunidade (VIANNA, 2011; VIANNA \& LOPES, 2012). Para fins de ilustração, reproduzemse aqui os resultados discutidos em Zilles (2007, p. 35-36), a partir da análise de dois corpora de fala referentes à cidade de Porto Alegre. ${ }^{6}$ A Tabela 6 sintetiza os resultados da produtividade de a gente sujeito segundo duas faixas etárias: jovens e velhos; e o Gráfico 1, em seguida, ilustra os resultados obtidos em estudo de tendências:

\footnotetext{
${ }^{6} \mathrm{~A}$ escolha por esses resultados referentes a uma localidade diferente da nossa não é aleatória, mas tenciona constatar que o fenômeno não é restrito ao Rio de Janeiro de onde provêm nossos dados.
} 


\section{TABELA 6}

$\mathrm{O}$ uso de a gente segundo a faixa etária

\begin{tabular}{l|c|c}
\hline Faixas etárias & Frequência & PR \\
\hline Jovens (de 25 a 44 anos) & $633 / 865=73 \%$ & 0.64 \\
Velhos (de 45 a 69 anos) & $358 / 668=54 \%$ & 0.32 \\
\hline
\end{tabular}

Fonte: Zilles (2007, p. 35) ${ }^{7}$

Na análise de Zilles (2007), chama à atenção a enorme diferença entre as duas faixas etárias controladas ( 0.64 dos jovens, em oposição a 0.32 dos velhos), que dá ideia da força do processo de mudança que tende a substituir nós por a gente no $\mathrm{PB}$, principalmente em função do incremento produzido pelo uso dos mais jovens. No Gráfico $1,{ }^{8}$ por sua vez, é possível constatar o acelerado avanço de uso de a gente em lugar de nós na posição de sujeito:

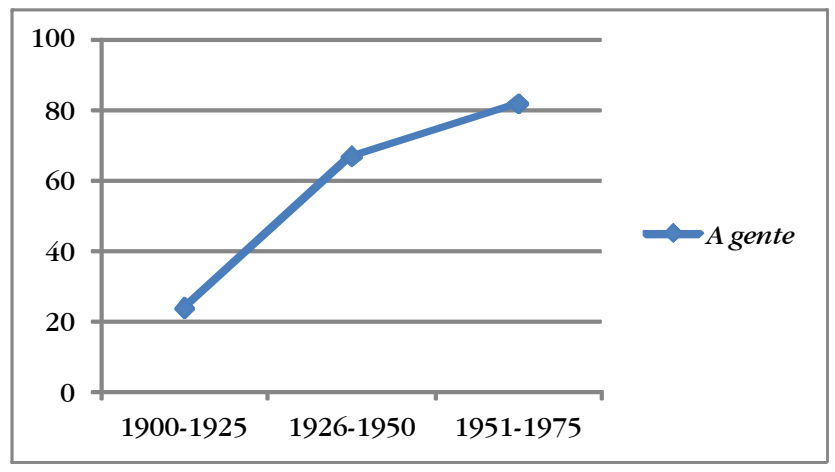

GRÁFICO 1: Percentuais de a gente segundo a data de nascimento do falante Fonte: Zilles (2007, p. 36) ${ }^{9}$

\footnotetext{
7 Título da tabela na fonte: "Fatores sociais significativos no uso de a gente, estudo de tendência, 1970 e 1990 (dados do NURC e do VARSUL)".

${ }^{8}$ Os dados utilizados provêm do estudo de tendências, com base nas amostras do NURC e do VARSUL da cidade de Porto Alegre, com os falantes segundo a sua data de nascimento (ZILLES, 2007).

${ }^{9}$ Título do gráfico na fonte: "Percentuais de uso de $a$ gente conforme o ano de nascimento dos falantes, estudo de tendência (dados do NURC e do VARSUL de Porto Alegre)".
} 
Os resultados demonstram claramente a evolução nas taxas de uso de a gente no estudo de tendências. No início do século XX, esses valores não excediam muito os $20 \%$ de frequência; entretanto, 50 anos depois, esses valores praticamente quadriplicaram, superando os $80 \%$ de produtividade. $^{10}$

Nesse sentido, os resultados aferidos para a aplicação de $a$ gente nas funções de complemento e adjunto estão de acordo com o processo mais geral de substituição de nós por a gente que caracteriza o PB. Nos dois casos, as faixas etárias mais jovens lideram o processo de inserção da forma inovadora no $\mathrm{PB}$, seja na função de sujeito, seja nas demais funções sintáticas. Em outras palavras, no caso do comportamento de a gente como complemento e adjunto, a análise da comunidade no tempo aparente também indica uma mudança em progresso.

\subsection{Escolaridade do informante}

Outro fator social que teve destaque na presente investigação refere-se à variável escolaridade. Conforme mencionado anteriormente, foram controlados três níveis de escolarização nas amostras do PB: (i) ensino fundamental; (ii) ensino médio; e (iii) ensino superior. A Tabela 7 sintetiza os resultados aferidos em nossa amostra, reunindo todos os dados obtidos:

\footnotetext{
${ }^{10}$ É digno de nota que padrões de comportamento bastante semelhantes foram localizados por Lopes (1993) em dados de diferentes localidades do Brasil (Rio de Janeiro, Porto Alegre e Salvador) e nos estudos de tempo real e tempo aparente com dados de falantes cultos do Rio de Janeiro (LOPES, 2003, p. 148). O trabalho pioneiro de Omena (1986) com falantes de escolaridade mediana no Rio de Janeiro também confirmam o observado por Zilles (2007) para Porto Alegre.
} 
TABELA 7

Escolaridade do informante

\begin{tabular}{l|c|c}
\hline & Freq. & PR \\
\hline Ensino fundamental & $27 / 93$ & \\
& $29 \%$ & 0.53 \\
Ensino médio & $23 / 42$ & \\
& $54 \%$ & 0.72 \\
Ensino superior & $26 / 94$ & \\
& $27 \%$ & 0.36 \\
\hline
\end{tabular}

Fator de aplicação: a gente.

De acordo com os resultados encontrados, é possível perceber o favorecimento de a gente como complemento e adjunto entre informantes com o ensino médio. Nesse grupo, localizaramse 23 dados de a gente, em 42 ocorrências totais, ou seja, houve $54 \%$ de frequência da forma inovadora em funções sintáticas diferentes de sujeito, com PR 0.72 .

No que se refere ao ensino superior, inversamente, houve o desfavorecimento à aplicação da regra, registando o peso relativo de 0.36. Foram encontrados apenas 26 dados de a gente em outras funções sintáticas, em 94 ocorrências localizadas no ensino médio: $27 \%$ de frequência.

Por sua vez, no ensino fundamental, os resultados aferidos mostram-se contraditórios. Ainda que o peso relativo indique o favorecimento à aplicação da regra (PR 0.53), a produtividade dos dados foi relativamente baixa: $29 \%$. A indicação do ensino fundamental como fator favorecedor à aplicação da regra talvez ocorra devido à interação com outro grupo de fatores, possivelmente o relativo à faixa etária. 


\subsection{Em suma, o que podemos dizer sobre a variação entre nós e a gente como complemento e adjunto?}

Com relação ao encaixamento linguístico e social da forma gramaticalizada no $\mathrm{PB}$, tendo em vista as funções sintáticas de complemento/adjunto do verbo e do nome, nossos resultados evidenciaram a reconfiguração do quadro pronominal do português brasileiro como apontaram Omena (1986) e Lopes (2003), confirmando o avanço de $a$ gente em alguns contextos mais do que em outros. A pesquisa empírica revelou as seguintes tendências:

(i) A forma inovadora a gente foi a estratégia preferencial no desempenho oral dos entrevistados na amostra constituída, quando se tem em vista o sintagma verbal. No interior do sintagma nominal, o uso das formas do paradigma de nós ainda são mais frequentes.

(ii) Entre as possíveis de relações gramaticais estabelecidas com a forma inovadora, a de (oblíquo) complemento favoreceu o emprego de a gente, seja em sintagmas oracionais seja em nominais.

(iii) O paralelismo formal mostrou-se relevante para o uso de $a$ gente também quando se têm em vista as funções sintáticas de complemento e adjunto. Todavia, o que mais propiciou o emprego de a gente em outras funções sintáticas foi o uso de $a$ gente na oração anterior, também em outra função sintática diferente da de sujeito.

(iv) Com relação às faixas etárias, o comportamento de $a$ gente nas funções sintáticas menos produtivas (nãosujeito) foi bastante semelhante ao que se observa em inúmeras pesquisas com relação à função de sujeito (VIANNA \& LOPES, 2012). No PB, quando se tem em vista a função de sujeito, há claros indícios de mudança linguística em curso, com crescente substituição de nós por a gente, impulsionada principalmente pelos jovens. 
No que se refere às outras funções sintáticas, de maneira geral, acontece o mesmo.

(v) O uso de a gente foi mais produtivo entre indivíduos de baixa e média escolaridade na amostra. A explicação para esse comportamento ainda precisa de maiores investigações.

\section{Considerações finais}

Ao que tudo indica, não é apenas na função de sujeito que o processo de implementação do a gente pronominal se encontra a pleno vapor no PB. Quando se têm em vista as funções de complemento e adjunto, o a gente pronominal também se encontra em competição com as formas do paradigma de nós. No entanto, encontram-se distinções entre os diferentes níveis sintáticos: de acordo com os resultados aferidos, as relações estabelecidas no sintagma verbal são mais abertas à entrada da forma inovadora do que as relações sintáticas no sintagma nominal, como já mostrava Omena (1986).

\section{Referências}

ÁLBAN, M. R.; FREITAS, J. Nós ou a gente? Estudos Linguísticos e Literários, Salvador, n. 11, p. 75-89, 1991.

AVERBUG, M. C. G. Objeto direto anafórico e sujeito pronominal na escrita de estudantes. Dissertação (Mestrado) - Universidade Federal do Rio de Janeiro, Rio de Janeiro, 2000.

BALTOR, C. da S. Estudo variacionista do objeto direto de terceira pessoa em série anafórica no falar pessoense. Dissertação (Mestrado) - Universidade Federal da Paraíba, João Pessoa, 2003.

BORBA, L. R. Alguns aspectos sobre o uso de "nós" e "a gente" em Curitiba. Fragmenta, Curitiba, n. 10, p. 65-76, 1993. 
BORGES, P. R. S. A gramaticalização de a gente no português brasileiro: análise bistórico-social-linguística da fala das comunidades gaúchas de Jaguarão e Pelotas. Tese (Doutorado em Língua Portuguesa) Universidade Federal do Rio Grande do Sul, Porto Alegre, 2004.

CORRÊA, V. R. Objeto direto nulo no português do Brasil. Dissertação (Mestrado) - Universidade Estadual de Campinas, Campinas, 1991.

CYRINO, S. O objeto nulo no português do Brasil: um estudo sintáticodiacrônico. Londrina: Ed. da UEL, 1997.

DUARTE, M. E. L. Variação e sintaxe: clítico acusativo, pronome lexical e categoria vazia no português do Brasil. Dissertação (Mestrado) Pontifícia Universidade Católica de São Paulo, São Paulo, 1986.

DUARTE, M. E. L. Clítico acusativo, pronome lexical e categoria vazia no português do Brasil. In: TARALlO, F. (Org.) Fotografias sociolinguísticas. Campinas: Pontes, 1989. p. 19-34.

DUARTE, M. E. L. A perda do princípio "evite pronome" no português brasileiro. Tese (Doutorado) - Universidade Estadual de Campinas, Campinas, 1995.

FERNANDES, E. A. Nós e a gente: variação na cidade de João Pessoa. Dissertação (Mestrado) - Universidade Federal da Paraíba, João Pessoa, 1997.

FERNANDES, E. A. Fenômeno variável: nós e a gente. In: HORA, D. da (Org.) Estudos sociolinguísticos: perfil de uma comunidade. Santa Maria: Pallotti, 2004. p. 149-156.

FREIRE, G. C. (2000) Os clíticos de terceira pessoa e as estratégias para sua substituição na fala culta brasileira e lusitana. Dissertação (Mestrado) - Universidade Federal do Rio de Janeiro, Rio de Janeiro, 2000.

FREIRE, G. C. A realização do acusativo e dativo anafóricos na escrita brasileira e lusitana. Tese (Doutorado) - Universidade Federal do Rio de Janeiro, Rio de Janeiro, 2005.

FREITAS, J. Nós e a gente em elocuções formais. Estudos Linguísticos e Literários, Salvador, n. 11, p. 91-102, 1991.

HEINE, B. Grammaticalization. In: JOSEPH, B.; JANDA, R. D. (Eds.) The handbook of historical linguistics. Oxford: Blackwell, 2003. p. 575-601. 
LAUREANO, D. C. A variação dos pronomes de primeira pessoa do plural na posição de sujeito: nós $e$ a gente. Dissertação (Mestrado em Linguística) - Universidade Federal de Santa Catarina, Florianópolis, 2003.

LOPES, C. R. dos S. Nós e a gente no português falado culto do Brasil. Dissertação (Mestrado em Língua Portuguesa) - Universidade Federal do Rio de Janeiro, Rio de Janeiro, 1993.

LOPES, C. R. dos S. A inserção de "a gente" no quadro pronominal do português. Frankfurt/Madri: Vervuert/Iberoamericana, 2003. V. 18.

LOPES, C. R. dos S. Pronomes pessoais. In: BRANDÃO, S. F.; VIEIRA, S. R. (Orgs.) Ensino de gramática: descrição e uso. São Paulo, Contexto, 2007, v. 1, p. 103-119.

MACHADO, M. S. Sujeitos pronominais "nós" e "a gente": variação em dialetos populares do norte fluminense. Dissertação (Mestrado em Língua Portuguesa) - Universidade Federal do Rio de Janeiro, Rio de Janeiro, 1995.

MAIA, F. P. S. A variação "nós”/“a gente” no dialeto mineiro: investigando a transição. Dissertação (Mestrado em Estudos Linguísticos) Universidade Federal de Minas Gerais, Belo Horizonte, 2003.

MATEUS, M. H. M.; BRITO, A. M.; DUARTE, I. Gramática da língua portuguesa. Lisboa: Caminho, 2003

MATTOS, S. E. R. . A primeira pessoa do plural em Goiás. In: SIMPÓSIO MUNDIAL DE ESTUDOS DE LÍNGUA PORTUGUESA: LÍNGUA PORTUGUESA: ULTRAPASSAR FRONTEIRAS, JUNTAR CULTURAS, II, Évora, 6-11 outubro 2009. Anais... Évora: Universidade de Évora, 2009.

MENDES, R. P. S. O perfil da alternância do sujeito nós $e$ a gente em Santo Antônio de Jesus: um recorte no português popular do interior da Bahia. Dissertação (Mestrado em Letras e Linguística) Universidade Federal da Bahia, Salvador, 2007.

MENDONÇA, A. K. Nós e a gente em Vitória: análise sociolinguística da fala capixaba. Dissertação (Mestrado em Estudos Linguísticos) Universidade Federal do Espírito Santo, Vitória, 2010.

MENON, O. P. S. Analyse sociolinguistique de l'indétermination du sujet dans le portugais parlé au Brésil, à partir des données du NURC/ $S P$. Tese (Doutorado) - Université de Paris VII, Paris, 1994. 
OMENA, N. P. A referência variável da primeira pessoa do discurso no plural. In: NARO, A. J. et al. Relatório final de pesquisa: Projeto Subsídios do Projeto Censo à Educação. Rio de Janeiro, Ed. da UFRJ, 1986. V. 2, p. 286-319.

OMENA, N. P. A referência à primeira pessoa do discurso no plural. In: OLIVEIRA E SILVA, G. M.; SCHERRE, M. M. Padrões sociolinguísticos: estudos de fenômenos variáveis do português falado na cidade do Rio de Janeiro. Rio de Janeiro, Ed. da UFRJ, 1996, p. 183-215.

OMENA, N. P. A referência à primeira pessoa do plural: variação ou mudança?. In: PAIVA, M. C. \& DUARTE, M. E. L. (Orgs.) Mudança linguística em tempo real. Rio de Janeiro: Contra Capa, 2003. p. 63-80.

RAMOS, C. M. A; BEZERRA, J R. M. \& ROCHA, M. F. S. Do nosso cotidiano ou do cotidiano da gente? Um estudo da alternância nós/a gente no português do Maranhão. Signum: Estudos da Linguagem, Londrina, v. 12, n. 1, p. 279-292, 2009.

ROCHA, F. C. F. A alternância nos pronomes pessoais e possessivos do português de Belo Horizonte. Dissertação (Mestrado em Linguística e Língua Portuguesa) - Pontifícia Universidade Católica de Minas Gerais, Belo Horizonte, 2009.

SEARA, I. C. A variação do sujeito nós e a gente na fala florianopolitana. Organon, Porto Alegre, v. 14, n. 28/29, p. 179-194, 2000.

SILVA, M. C. de F. O objeto direto anafórico no dialeto rural afrobrasileiro. Dissertação (Mestrado) - Universidade Federal da Bahia, Salvador, 2004.

TAMANINE, A. M. B. A alternância nós/a gente no interior de Santa Catarina. Dissertação (Mestrado em Letras) - Universidade Federal do Paraná, Curitiba, 2002.

TAMANINE, A. M. B. Curitiba da gente: um estudo sobre a variação pronominal nós/a gente e a gramaticalização de a gente na cidade de Curitiba-PR. Tese (Doutorado em Letras) - Universidade Federal do Paraná, Curitiba, 2010.

VIANNA, J. B. S. Semelhanças e diferenças na implementação de a gente em variedades do português. Tese (Doutorado em Língua Portuguesa) - Universidade Federal do Rio de Janeiro, Rio de Janeiro, 2011. 
VIANNA, J. B. S. A implementação de a gente nas funções sintáticas de acusativo, dativo e oblíquo: reflexões, propostas e primeiros resultados. Rio de Janeiro: Programa de Pós-Graduação em Letras Vernáculas da Universidade Federal do Rio de Janeiro, 2012. (Relatório final de Pós-Doutoramento Júnior financiado pelo CNPq)

VIANNA, J. B. S.; LOPES, C. R. dos S. Para um panorama do processo de substituição de nós por a gente no português brasileiro. Niterói, 2012. (Comunicação apresentada no GT de Sociolinguística no XXVII ENANPOLL, realizado na Universidade Federal Fluminense, em Niterói, no período de 10 a 13 de julho de 2012).

ZILLES, A. M. S. The development of a new pronoun: the linguistic and social embedding of "a gente" in Brazilian Portuguese. Language Variation and Change, Philadelphia, v. 17, p. 19-53, 2005.

ZILLES, A. M. S. O que a fala e a escrita nos dizem sobre a avaliação social do uso de a gente? Letras de Hoje, Porto Alegre, v. 42, n. 2, p. 27-44, 2007.

Recebido para publicação em 31 de agosto de 2012 Aprovado em 13 de outubro de 2012 